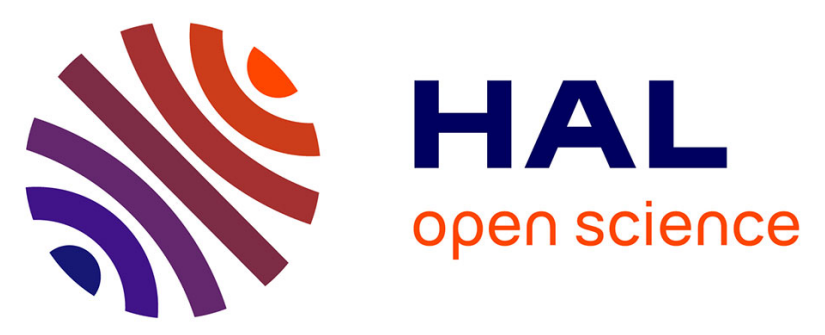

\title{
A new finite element method for inverse problems in structural analysis: application to atherosclerotic plaque elasticity reconstruction
}

Adeline I Bouvier, Flavien I Deleaval, Marvin M Doyley, Antoine I Tacheau, Gérard I Finet, Simon Lefloch, Guy I Cloutier, Roderic I Pettigrew, Jacques I

Ohayon

\section{To cite this version:}

Adeline I Bouvier, Flavien I Deleaval, Marvin M Doyley, Antoine I Tacheau, Gérard I Finet, et al.. A new finite element method for inverse problems in structural analysis: application to atherosclerotic plaque elasticity reconstruction. 39ème congrès de la société de Biomécanique, Aug 2014, Valenciennes, France. pp.16-17, 10.1080/10255842.2014.931071 . hal-01576910

\section{HAL Id: hal-01576910 https://hal.science/hal-01576910}

Submitted on 24 Aug 2017

HAL is a multi-disciplinary open access archive for the deposit and dissemination of scientific research documents, whether they are published or not. The documents may come from teaching and research institutions in France or abroad, or from public or private research centers.
L'archive ouverte pluridisciplinaire HAL, est destinée au dépôt et à la diffusion de documents scientifiques de niveau recherche, publiés ou non, émanant des établissements d'enseignement et de recherche français ou étrangers, des laboratoires publics ou privés. 


\title{
A new finite element method for inverse problems in structural analysis: application to atherosclerotic plaque elasticity reconstruction
}

\author{
Adeline Bouvier ${ }^{\mathrm{a}, \mathrm{b}}$, Flavien Deleaval ${ }^{\mathrm{b}}$, Marvin M. Doyley ${ }^{\mathrm{c}}$, Antoine Tacheau ${ }^{\mathrm{b}}$, Gérard Finet ${ }^{\mathrm{d}}$, Simon Le Floc'h $^{\mathrm{e}}$, \\ Guy Cloutier ${ }^{\mathrm{f}}$, Roderic I Pettigrew ${ }^{\mathrm{g}}$ and Jacques Ohayon ${ }^{\mathrm{b}, \mathrm{h} *}$ \\ ${ }^{a}$ Laboratoire LAMA,Université de Savoie CNRS UMR 5127, Chambéry, France; ${ }^{b}$ Laboratoire TIMC-IMAGUJF, CNRS UMR 5525, \\ Grenoble, France; ${ }^{c}$ University of Rochester, Rochester NY, USA; ${ }^{d}$ Hospices Civils de Lyon INSERM Unit 886, Université Claude \\ Bernard,Lyon, France; ${ }^{e}$ Laboratoire LMGC, Université de Montpellier II, CNRS UMR 5508, Montpellier, France; ${ }^{f}$ Laboratoire LBUM, \\ Université de Montréal, CRCHUM, Montréal, Québec, Canada; ${ }^{g}$ National Institutes of Health NIBIB, Bethesda, MD, USA; ${ }^{h}$ Université \\ de Savoie, Polytech Annecy-Chambéry, Chambéry, France
}

Keywords: atherosclerosis; finite element method; elastography; inverse problem

\section{Introduction}

Atherosclerotic plaque rupture remains the leading cause of acute coronary syndrome (ACS), myocardial infarction and stroke (Lloyd-Jones et al. 2010). Atherosclerotic lesions develop inside the arterial wall. Vulnerable plaque (VP), which is characterised by a relatively large extracellular necrotic core and a thin fibrous cap infiltrated by macrophages, is prone to rupture (Virmani et al. 2000). The rupture of the thin-cap fibroatheroma may lead to the formation of a thrombus, causing the acute syndrome and possibly death (Virmani et al. 2006). The disease remains asymptomatic for a long time, but early detection of vulnerable atherosclerotic lesions is a crucial step in preventing risk of rupture and managing ACS and strokes.

Accurate quantification of both morphology (Ohayon et al. 2008) and mechanical properties of the diseased arteries (Finet et al. 2004) are critical keys in the detection of VP. Indeed, peak cap stress (PCS) amplitude has been identified as the biomechanical key predictor of vulnerability to rupture (Finet et al. 2004). Quantifying PCS in vivo remains a challenge as it depends not only on the VP morphology, but also on the mechanical properties of the plaque components (Ohayon et al. 2008). Although several methods have been developed to extract the spatial strain distributions (Doyley et al. 2001; Maurice et al. 2004), the complex geometries of atherosclerotic plaques inhibit direct translation into plaque mechanical properties.

The present theoretical study was, therefore, designed to develop a finite element (FE) method-based direct computational algorithm for elasticity reconstruction problems that account for material discontinuities.

\section{Methods}

The proposed elasticity reconstruction algorithm was obtained by extending the nodal material properties (NMP) approach proposed by Oberai et al. (2003).
To model material discontinuities between FEs, we modified and adapted the extended FE (Xfem) method (Moës et al. 1999) to the NMP approach. This new direct atherosclerotic plaque elasticity reconstruction method, based on the original material-FE formulation allowing for material discontinuities (named NMP-Xfem ${ }^{-1}$ ), was applied to coronary lesions of patients imaged in vivo using intravascular ultrasound (IVUS) technique.

Seven patients underwent coronary IVUS, and the extracted plaque geometries were used to simulate displacement and strain fields from which the performance of the original direct elasticity reconstruction method NMP-Xfem ${ }^{-1}$ was tested.

For the purpose of this study, atherosclerotic plaque components were modelled as isotropic and quasiincompressible media with a linear elastic behaviour. The FE models were solved under the assumption of plane strain. The two-dimensional proposed algorithm was derived by using the standard-based displacement FE method. To account for material heterogeneities, we introduced the notion of discontinuous nodal enrichment as performed to model failure in structural analysis.

The Galerkin FE representation of the governing elasticity equations applied to this structure is given in matrix form by

$$
[\mathrm{K}(\lambda, \mu)]\{\mathrm{U}\}=\{\mathrm{F}\}
$$

where $\{F\}$ and $\{U\}$ are the nodal force and displacement vectors, respectively, and $\lambda$ and $\mu$ the Lamé's coefficients associated to the material properties of the FE, and $[\mathrm{K}]$ the global symmetric stiffness matrix. The displacement FE approximations are associated to regular mesh and are given by

$$
\begin{aligned}
& u(x)=\sum_{i \in I} u_{i} \varphi_{i}(x) \\
& v(x)=\sum_{i \in I} v_{i} \varphi_{i}(x)
\end{aligned}
$$


where $u$ and $v$ contain the components of the displacement vector, $u_{i}$ and $v_{i}$ the displacements at node $i, \varphi i$ the shape function associated with node $i$ and $x$ the position vector. The nodal enrichment approach allows to satisfy the material discontinuity constraint by introducing additional nodes, which increases the degree of freedom related to nodal material variables vector. As a consequence, the FE approximation of the two material constants (i.e. the two Lamé's coefficients $\lambda$ and $\mu$ of the FE) was expressed as

$$
\begin{aligned}
& \lambda(x)=\sum_{j \in J} \lambda_{j} \psi_{j}(x) \\
& \mu(x)=\sum_{j \in J} \mu_{j} \psi_{j}(x)
\end{aligned}
$$

where $I$ is the set of initial nodes $i$ (before enrichment), $J$ the set of all the nodes after the enrichment and $\lambda k$, $\mu k(k \in I, J)$ the components of the nodal material vectors $\{\lambda\}$ and $\{\mu\}$ respectively. The shape functions $\varphi i(i \in I$ and $\psi \mathrm{j}(j \in J)$ were used for displacement and material property fields respectively. This material-FE formulation allowing for material discontinuities (named NMP-Xfem) was used to solve the forward problem.

Taking advantage of the linear relationships between the nodal displacement and material variables, we reformulated the equations of the forward FE methodology $N M P$-Xfem to obtain the linear FE formulation of the inverse algorithm $N M P-X f^{-1} m^{-1}$. We extracted a matrix [Q] (named displacement matrix) that was used to solve for the nodal mechanical properties $\{\mathrm{R}\}$. We thus obtained the following set of linear equilibrium equations for the new linear inverse FE methodology:

$$
\left[\mathrm{Q}\left(u_{k}\right)\right]\{\mathrm{R}\}=\{\mathrm{F}\} \operatorname{avec}\{\mathrm{R}\}=\left\{\begin{array}{l}
\lambda \\
\mu
\end{array}\right\}
$$

and then solve for the global NMP $\{\mathrm{R}\}$ :

$$
\{R\}=\left(\left([Q]^{T}[Q]\right)^{-1}[Q]^{T}\right)\{F\}
$$

\section{Results and conclusion}

The performance of the new NMP-Xfem ${ }^{-1}$ method to recover Young modulus map and to deal with discontinuities with necrotic cores (nc) and calcification (ca) is shown in Figure 1. Results are compared with the $N M P^{-1}$ method. Both direct and inverse algorithms have been implemented in MATLAB. Strain fields resulting from the forward problem NMP-Xfem have been used as input data for the inverse problem $N M P-X \mathrm{fem}^{-1}$. Simulations were performed on VP geometries acquired by IVUS in vivo.

The novel method NMP-Xfem ${ }^{-1}$ was successfully applied to the seven coronary lesions of patients. Our results showed that the mean relative error of the reconstructed Young's moduli decreased from $103.29 \pm 111.86 \%$ to $(2.6 \pm 5.7) \times 10^{-8 \%}$ (i.e. close to the exact solution) when considering the enriched nodes instead of the $N M P^{-1}$ method. Figure 1 shows clearly that
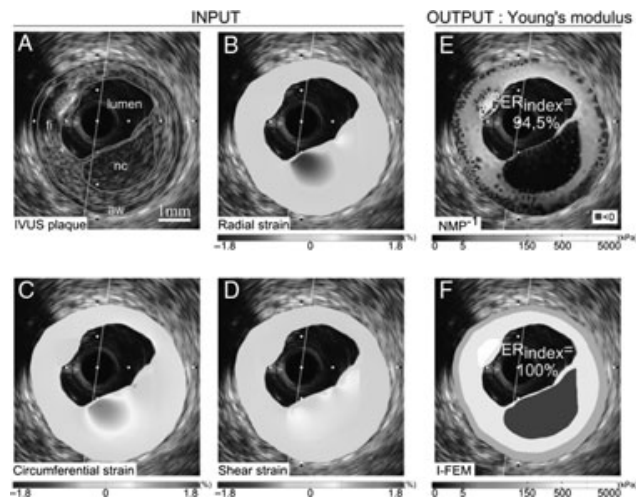

Figure 1. (A) IVUS acquisition. (B)-(D) Input data: simulated radial, circumferential and shear strain fields, respectively. (E) and $(\mathrm{F})$ Young's modulus reconstruction maps obtained with $\mathrm{NMP}^{-1}$ and NMP-Xfem ${ }^{-1}$, respectively.

the combined inverse approach $N M P-\mathrm{Xfem}^{-1}$ allows for material discontinuities. Moreover, no negative values of Young's modulus were obtained by using the proposed inverse method NMP-Xfem ${ }^{-1}$.

\section{Acknowledgements}

This new FE code has been patented (UJF-Floralis 2013).

\section{References}

Doyley MM, Mastik F, de Korte CL, Carlier SG, Céspedes EI, Serruys PW, Bom N, van der Steen AF. 2001. Advancing intravascular ultrasonic palpation toward clinical applications. Ultrasound Med Biol. 27:1471-1480.

Finet G, Ohayon J, Rioufol G. 2004. Biomechanical interaction between cap thickness, lipid core composition and blood pressure in vulnerable coronary plaque. Coron Artery Dis. $15: 13-20$.

Lloyd-Jones D, Adams RJ, Brown TM, Carnethon M, Dai S, DeSimone G, Ferguson TB, Ford E, Furie K, Gillespie C, et al. 2010. Executive summary: heart disease and stroke statistics - 2010 update. A report from the American Heart Association. Circulation. 121:948-954.

Maurice RL, Ohayon J, Finet G, Cloutier G. 2004. Adapting the Lagrangian speckle model estimator for endovascular elastography: theory and validation with simulated radiofrequency data. J AcoustSoc Am. 116:1276-1286.

Moës N, Dolbow J, Belytschko T. 1999. A finite element methods for crack growth without remeshing. Int $\mathrm{J}$ Numer Methods Eng. 46:131-150.

Oberai AA, Gokhale NH, Feijóo GR. 2003. Solution of inverse problems in elasticity imaging using the adjoint method. Inverse Problem. 19:297-313.

Ohayon J, Finet G, Gharib AM, Herzka DA, Tracqui P, Heroux J, Rioufol G, Kotys MS, Elagha A, Pettigrew RI. 2008. Necrotic core thickness and positive arterial remodeling index: emergent biomechanical factors for evaluating the risk of plaque rupture. Am J Physiol Heart Circ Physiol. 295:H717-H727.

Virmani R, Burke AP, Farb A, Kolodgie FD. 2006. Pathology of the vulnerable plaque. J Am Coll Cardiol. 47:C13-C18.

Virmani R, Kolodgie FD, Burke AP, Farb A, Schwartz SM. 2000. Lessons from sudden coronary death: a comprehensive morphological classification scheme for atherosclerotic lesions. Arterioscler Thromb Vasc Biol. 20:1262-1267. 